\title{
The WHO African Region: Research Priorities on Sexual and Reproductive Health and Rights
}

\author{
Leopold Ouedraogo ${ }^{*}$, Triphonie Nkurunziza1, Assumpta Muriithi1, Theopista Kabuteni John', \\ Chilanga Asmani1, Hayfa Elamin1, Symplice Mbola Mbassi', Souleymane Zan', \\ Bigirimana Françoise1, Mihretu Belete', Gbenou Dina1, Dadji Kwami', Kim Caron Rahn², \\ Ali Moazzam², Tolu Lemi², Blami Dao3 ${ }^{3}$ Issiaka Sombie ${ }^{4}$, Okech Mollent ${ }^{5}$
}

\author{
${ }^{1}$ Reproductive, Maternal Health and Ageing, WHO Regional Office for Africa, Brazzaville, Congo \\ ${ }^{2}$ Department of Reproductive Health and Research, World Health Organization, Geneva, Switzerland \\ ${ }^{3}$ JHPIEGO, Ouagadougou, Burkina Faso \\ ${ }^{4}$ West Africa Health Organization, Ouagadougou, Burkina Faso \\ ${ }^{5}$ Peak Moments Global HR Solutions, Nairobi, Kenya \\ Email: `ouedraogol@who.int, nkurunzizat@who.int, kimca@who.int, alimoa@who.int, tolul@who.int, muriithia@who.int, \\ asmanic@who.int, bigirimanaf@who.int, elaminha@who.int, zans@who.int, gbenoud@who.int, tafesseb@who.int, \\ blami.dao@jhpiego.org, isombie@wahooas.org,dadjik@who.int, mollentakinyi@gmail.com
}

How to cite this paper: Ouedraogo, L., Nkurunziza, T., Mureithi, A., John, T.K., Asmani, C., Elamin, H., Mbassi, S.M., Zan, S., Françoise, B., Belete, M., Dina, G., Kwami, D., Rahn, K.C., Moazzam, A., Lemi, T., Dao, B., Sombie, I. and Mollent, O. (2021) The WHO African Region: Research Priorities on Sexual and Reproductive Health and Rights. Advances in Reproductive Sciences, 9, 13-23.

https://doi.org/10.4236/arsci.2021.91002

Received: October 24, 2020

Accepted: December 27, 2020

Published: December 30, 2020

Copyright $\odot 2021$ by author(s) and Scientific Research Publishing Inc. This work is licensed under the Creative Commons Attribution International License (CC BY 4.0).

http://creativecommons.org/licenses/by/4.0/

\begin{abstract}
Background: Many policy makers deliberating on comprehensive sexual and reproductive health and rights services need reliable evidence to make choices that benefit women, adolescents, children and the wider society. While universal health coverage discourse provides an opportunity to expand access through evidence based interventions, many gaps exist. Research prioritization has proved to be very helpful in identifying relevant areas especially in constrained resource settings. The purpose of this paper is to present the results of the World Health Organization Africa Region research prioritization for sexual and reproductive health and rights. These priorities hope to guide the region for the next three years. Methods: We used the Child Health and Nutrition Research Initiative approach to identify priority questions among many potential areas for research prioritization on sexual and reproductive health and rights. The implementation process was organized in three phases. The first phase involved sending out an online survey to various experts with experience in sexual and reproductive health rights. These questions were received by a technical team from World Health Organization headquarters for review. 634 questions were identified for potential research and grouped into 12 themes. The second phase involved experts who reviewed the questions. The team merged questions with duplications, removed the questions that were out of scope and finally refined the wordings. In the final phase, experts worked in groups to score and rank top ten priority questions for each of the
\end{abstract}


12 thematic areas. Results: A list of 120 priority questions for sexual and reproductive health and rights were prioritized by 67 participants drawn from 16 organizations. Most of the priority research questions (45\%) focused on the theme of gender-based violence, $35 \%$ prioritized services in sexual and reproductive health and rights in humanitarian settings while $15 \%$ prioritized preventing unsafe abortion. $5 \%$ of the participants prioritized cervical cancer prevalence, prevention and treatment as a thematic area out of the questions in the top 20 research priority questions. Conclusions: Key priority research questions in sexual and reproductive health and rights were identified around five themes. The priority list will be of significance to World Health Organization regional Office for Africa and her stakeholders for the next three years.

\section{Keywords}

Research Priorities, Sexual and Reproductive Health and Rights, Child Health and Nutrition Research Initiative

\section{Background}

Many global health and development initiatives call for action to improve sexual and reproductive health and rights (SRHR) [1]. The links of SRHR to gender equality and women's wellbeing, impact on maternal, newborn, child, and adolescent health. It also plays a role in shaping future economic development and environmental sustainability, thus making it essential [2] [3]. Indeed, progress towards fulfilling SRHR for all has been slow due to inadequate evidence to support relevant policy and programmatic decisions. Health care coverage decisions such as SHRH are complex, and well-defined research priorities could provide evidence to improve decision-making and accountability [3] [4].

Every year, billions of dollars are invested in health research and development [5]. However, only a small proportion of these funds address health issues like sexual reproductive health and rights which is one of the key components of the sustainable Development Goals (SDGs) [6] [7]. Increasing investments in health research have improved policy setting and practice, however, the gains in health have not been equitably distributed [8]. The mismatch between health researches that are responsive to health needs including SRHR and that which funders prioritize and invest in still remains a challenge. By strengthening strategies to increase access to evidence based SRHR interventions, countries can improve health.

According to the WHO's strategy on research for health, research prioritization is one of the four pillars. Research prioritization aims at increasing collaboration, coordination and overall investment directing funding toward research that addresses priority health needs. It is thus necessary for the region to prioritize key research areas that can benefit the countries due to constraints in resources. Africa faces unique health challenges made worse by demographic and 
epidemiologic changes, triple burden of disease, increasing healthcare costs, as well as shortage of health workers [9]. Such challenges have significant effects on health care delivery and health research systems. They require an evidence based health systems approach which focuses more attention primarily on the provision of comprehensive services within the universal health coverage (UHC) framework particularly SRHR for the most vulnerable populations including those living in humanitarian settings [10] [11] [12].

Priority setting for responsive interventions in health can be very complex and difficult for governments and humanitarian organizations and especially in sub Saharan Africa where one crisis occurs in multiples [13] [14]. For health research priority setting exercises to effectively target SRHR themes with the greatest public health benefit, it is important that they are of high quality. Therefore there is a need for consensus on what constitutes quality or good practice in this area.

Following a virtual survey from whose questions were circulated and collected in August, 2019, a workshop was held in Cape Town, South Africa, comprising of SRHR focal points and experts drawn from WHO priority Country Offices. Other involved included the academia, WHO collaborating centers, health organizations and researchers and in the region were involved in the brainstorming, identification and prioritization of specific SRHR research priorities. The meeting identified knowledge gaps in the WHO African Region and generated priority research areas through interactive consensus based discussions.

The discussion focused on country experiences on research implementation plans and strategies for strengthening research capacity in SRHR. The meeting identified key thematic areas and their related specific topics which included preventing unsafe abortion, gender based violence, family planning uptake and barriers, sexual and reproductive health and rights service delivery in humanitarian settings, adolescent sexual and reproductive health, cervical cancer prevalence, prevention and treatment, Sexually transmitted infections, maternal and newborn emergency care, mHealth and innovative strategies and best practices in sexual reproductive and health rights. The main aim of our priority setting exercise was to identify research questions with a probability of impacting SRHR interventions over the next three years. Universal access to SRHR is at the centre of the Sustainable Development Goals (SDGs) as it contributes to the achievements of the other SDGs. However, in Africa, the SRHR goals have continued to register little progress from the Millennium Development Goals (MDGs) and thus require more focus and attention through evidence based interventions from the identified priorities.

\section{Methods}

The research prioritization exercise adopted the Child Health and Nutrition Research Initiative (CHNRI) and was implemented in three phases: 1) Online generation and collection of potential research questions conducted in August 2019 
2) Reviewing the questions, consolidation and conducting thematic analysis conducted in September 2019 and 3) Scoring and ranking to identify priority research questions a using pre-defined scoring criteria. Figure 1 highlights the summary of the study flow. During the first phase of the process, a technical team from WHO Africa Regions sent out an online survey to experts to give their ideas on potential research areas. The experts were drawn from the academia, ministries of health from selected countries, researchers and representatives from intuitions that support sexual and reproductive health and rights. They were provided with a guideline to identify researchable questions that address the following qualities-answerability, effectiveness, deliverability, equity and those that have great potential impact to the populations and especially the vulnerable.

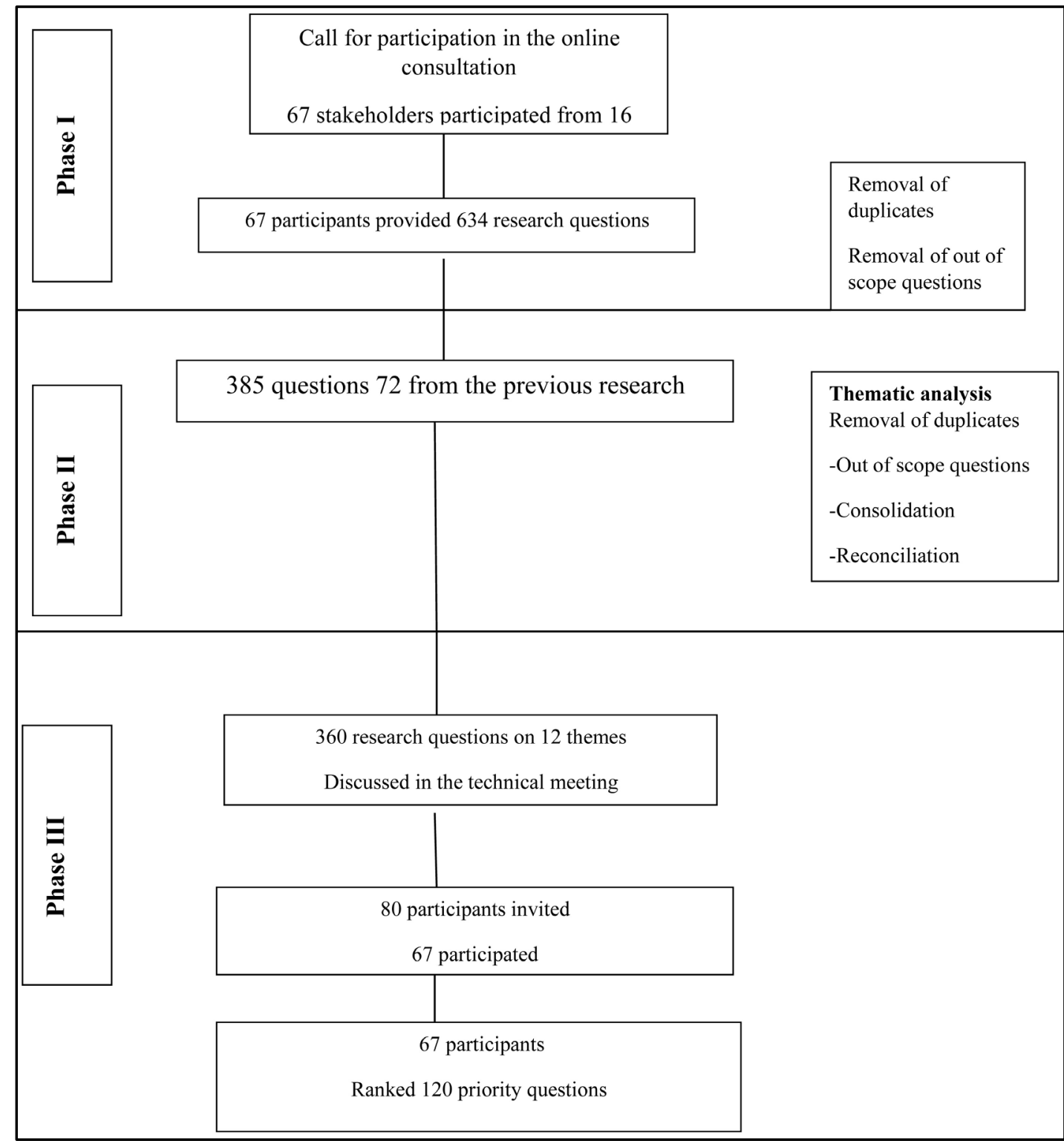

Figure 1. Summary of the study flow. 
The online survey was circulated and collected in August 2019. 634 potential research questions were consolidated thematically in September 2019 by a technical team from WHO headquarters into 12 core thematic areas in preparation for the second phase. The online survey built on the results from a prior research prioritization exercise conducted by EMRO and AFRO in 2016 [13]. The twelve themes are presented in Table 1.

The second and third phases of the prioritization exercise were conducted in a meeting held from $29^{\text {th }}$ October to $1^{\text {st }}$ November, 2019 in Cape Town-South Africa. A total of 67 Participants comprising of SRHR focal persons from selected countries, academia, research institutions, representation from WHO country offices, WHO collaborating centers and other health organizations attended the meeting. This was a response rate of $83.7 \%$. The participants were divided into twelve groups according to the 12 research themes.

The meeting utilized a modified CHNRI approach that comprised of four steps namely:

1) Policy makers and investors provided inputs by defining the context and the criteria for priority setting

2) Technical experts proposed, listed systematically and independently scored the research ideas

3) Stakeholders agreeing on differential weights for the chosen priority setting criteria taking into consideration the wider societal system of values

4) Consensus based computation and analysis of the scores by the experts and stakeholders.

The groups reviewed the research questions, added or removed duplications and the questions that were out of scope, ensured consistency in the wordings and where necessary created sub categories for the list of research questions. Finally, in the same groupings, the participants further refined and through consensus based approach, we scored the research questions according to the criteria in Table 2. For each research question, the individual scores of each criterion were summed up. No special weighting was applied to the criteria. The lowest score was 1 while the highest score was 5 . Each question could therefore attain a lowest score of 6 or highest score of 30 .

Table 1. Thematic areas.

\begin{tabular}{ll}
\hline \multicolumn{1}{c}{ Thematic Areas } & \multicolumn{1}{c}{ Thematic Areas } \\
\hline Implement best practices for SRHR & $\begin{array}{l}\text { Cervical cancer prevalence, prevention and treatment } \\
\text { Sexual and reproductive health and rights services in } \\
\text { humanitarian settings }\end{array}$ \\
Preventing unsafe abortion & $\begin{array}{l}\text { Improving care for mothers and children during } \\
\text { childbirth. }\end{array}$ \\
Family planning. & $\begin{array}{l}\text { Improving maternal and newborn emergency care. } \\
\text { Infertility }\end{array}$ \\
$\begin{array}{l}\text { Sexually Transmitted infections (STI) } \\
\text { prevalence, prevention and treatment }\end{array}$ & Addressing gender based violence \\
Adolescent sexual and reproductive health & mHealth and innovative strategies \\
\hline
\end{tabular}


Table 2. Scoring criteria.

\begin{tabular}{clc}
\hline \multicolumn{1}{c}{ Criteria } & \multicolumn{1}{c}{ Definition } & \multicolumn{1}{c}{ Scoring } \\
\hline 1) Magnitude & $\begin{array}{l}\text { Magnitude of the problem; in terms of the proportion of the } \\
\text { population, such as women, under } 5 \text { children, elderly, are affected. }\end{array}$ & $1-2-3-4-5$ \\
& Of the condition; i.e. danger to the individual and the community. & \\
2) Severity & $\begin{array}{l}\text { How serious is the condition. Does it threaten life, cause major } \\
\text { suffering, and decrease the ability to lead a normal life. }\end{array}$ & $1-2-3-4-5$ \\
& $\begin{array}{l}\text { Based on the best existing evidence and knowledge, would } \\
\text { 3) Effectiveness }\end{array}$ & $\begin{array}{l}\text { intervention be efficacious in reducing disease burden? It is likely to } \\
\text { be effective under programme conditions }\end{array}$ \\
& $\begin{array}{l}\text { Taking into account a) the infrastructure and resources required to } \\
\text { deliver effective interventions (e.g. human resources, health facilities, } \\
\text { communication and transport infrastructure), and b) the need for } \\
\text { change in demand, beliefs and attitudes of users, would you say that } \\
\text { the endpoints of the research would be deliverable? affordability and } \\
\text { sustainability }\end{array}$ & $1-2-3-4-5$ \\
& $\begin{array}{l}\text { Diseases burden reduction; taking into account the best available } \\
\text { information, would you say that reaching of research endpoints } \\
\text { would eventually, have a "capacity" to impact directly and indirectly } \\
\text { disease burden. E.g. up to 5\% to 10\% reduction in long run. }\end{array}$ & $1-2-3-4-5$ \\
5) Burden & $\begin{array}{l}\text { Equity enhancing; does the intervention affect mainly the } \\
\text { underprivileged in the population? Intervention has potential to } \\
\text { improve equity in disease burden distribution in the longer term? }\end{array}$ & $1-2-3-4-5$ \\
\hline
\end{tabular}

1 is the lowest score and 5 the highest score. Each question could therefore attain a lowest score of 6 or highest score of 30 .

\section{Results}

The research prioritization exercise aimed at developing a comprehensive list of priority research areas in SRHR that the WHO Africa Region would focus on in three next coming years. In this paper, we report the results of the research prioritization exercise on SRHR focusing on five themes. The themes include sexual and reproductive health and rights services in humanitarian settings; Addressing gender based violence, cervical cancer prevalence, prevention and treatment, preventing unsafe abortion, and mHealth and innovative strategies.

The five thematic areas generated a total of 219 research questions which were scored according to the criteria described in Table 2 and ranked by experts. A total of ten priority questions for each of the five themes were identified. Figure 2 presents the distribution of the questions by thematic area in the top 20 priorities. Addressing gender-based violence had the highest number of priority questions (45\%) among the top 20 ranked questions from five thematic areas. This was followed by service delivery for sexual and reproductive health and rights in humanitarian settings (35\%). Preventing unsafe abortion (15\%) and cervical cancer prevention and treatment $(5 \%)$. mHealth and innovative strategies was not represented in the top 20 priority questions but it still comprised of $8 \%$ of the questions in the upper quartile with more than $75 \%$.

The top ranked questions in the five thematic areas are presented in Table 3. 
Table 3. Top 20 (highest scoring) research priority questions to improve sexual and reproductive health.

\begin{tabular}{|c|c|c|}
\hline Questions & NRPs & Thematic areas \\
\hline $\begin{array}{l}\text { Determine the prevalence and associated factors of unwanted pregnancies and abortions } \\
\text { performed under conditions of humanitarian emergency. }\end{array}$ & 100 & SRHR services in humanitarian settings \\
\hline Evidence on gender-based violence in humanitarian situations and associated factors; & 100 & SRHR services in humanitarian settings \\
\hline Define an optimal model for coordinating SRHR interventions and responders in crisis situations & 100 & SRHR services in humanitarian settings \\
\hline $\begin{array}{l}\text { Engage young adolescents in behavioral interventions to influence gender roles - Longitudinal } \\
\text { prospective trials. }\end{array}$ & 100 & Addressing gender-based violence \\
\hline $\begin{array}{l}\text { Analysis of the determinants of gender-based violence? FGM, early marriage, pedophilia, } \\
\text { domestic violence, domestic violence, domestic violence and sexual violence }\end{array}$ & 100 & Addressing gender-based violence \\
\hline Short-term and long-term complications of GBV among survivors. & 100 & Addressing gender-based violence \\
\hline Assess the effectiveness of men's engagement in addressing gender-based violence against women & 100 & Addressing gender-based violence \\
\hline Assess the scope and operational capacities of psychosocial services in humanitarian situations; & 91 & SRHR services in humanitarian settings \\
\hline $\begin{array}{l}\text { Assessment of the extent and strategies to prevent gender-based violence in the context of } \\
\text { humanitarian crises. }\end{array}$ & 91 & Addressing gender-based violence \\
\hline $\begin{array}{l}\text { Evaluate the effectiveness of interventions (e.g. counselling or incentives, or home visits) to } \\
\text { increase post-abortion contraception uptake and continuance, and reduce repeat abortion, on } \\
\text { improving maternal health outcomes. }\end{array}$ & 91 & Preventing unsafe abortion \\
\hline $\begin{array}{l}\text { Evaluate community-based awareness programs to reduce unwanted pregnancies and } \\
\text { encourage women to seek help early. }\end{array}$ & 91 & Preventing unsafe abortion \\
\hline $\begin{array}{l}\text { Evaluate the effectiveness of strategies implemented to improve access to information and the } \\
\text { provision of SRH services for adolescents in humanitarian situations? }\end{array}$ & 86 & SRHR services in humanitarian settings \\
\hline $\begin{array}{l}\text { Assess the availability of SRHR services required in humanitarian situations under the six pillars } \\
\text { of the health system; }\end{array}$ & 86 & SRHR services in humanitarian settings \\
\hline Assess providers' SRH knowledge and practices in all phases of crisis in a humanitarian emergency; & 86 & SRHR services in humanitarian settings \\
\hline $\begin{array}{l}\text { Attitude and perceptions of the community (civil society, associations, political leaders, } \\
\text { religious and customary leaders) and health providers towards GBV }\end{array}$ & 86 & Addressing gender-based violence \\
\hline $\begin{array}{l}\text { Evaluate the impact and cost-effectiveness of the implementation of GBV prevention and } \\
\text { management policies on maternal and perinatal health. }\end{array}$ & 86 & Addressing gender-based violence \\
\hline Provision of care, availability of appropriate services on GBV & 86 & Addressing gender-based violence \\
\hline Inter-sectoral collaboration in the management of GBV (health, security, social work, legal,) & 86 & Addressing gender-based violence \\
\hline $\begin{array}{l}\text { Cost-benefit analysis of systematic HPV vaccination compared to the current cost of cervical } \\
\text { cancer in public health care systems (relevant for countries); }\end{array}$ & 86 & $\begin{array}{l}\text { Cervical cancer prevalence, prevention } \\
\text { and treatment }\end{array}$ \\
\hline Community and client's perception towards accessible safe and post abortion services. & 86 & Preventing unsafe abortion \\
\hline
\end{tabular}

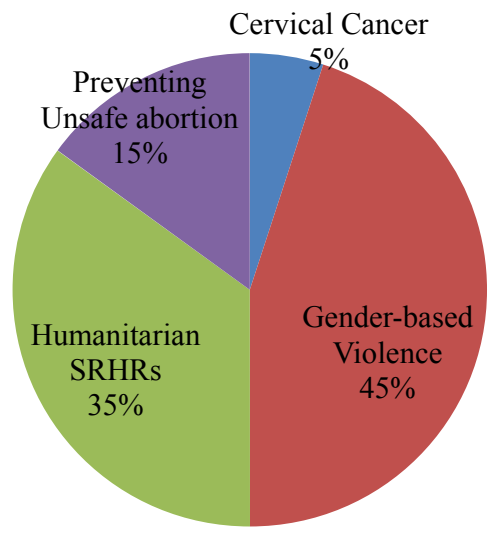

Figure 2. Distribution of priority research questions by theme. 
Addressing gender-based violence made up to $45 \%(n=9)$ of the top 20 list with other major themes including service delivery of SRHR in humanitarian settings $(n=7)$, preventing unsafe abortion $(n=3)$ and cervical cancer prevalence, prevention and treatment $(n=1)$. mHealth and innovative strategies did not appear in the top-20 list but comprised $8 \%$ of the questions in the upper quartile (questions that had NRP scores greater than 75).

\section{Discussion}

The research prioritization process identified key research areas that needed emphasis in the WHO Africa Region. Despite the fact that researchers agree that identifying priorities for research in any area can be a demanding and complex task, the results show that a group of diverse experiences and backgrounds still came a consensus and identified relevant areas based on a criteria. The list is comparable to a research prioritization exercise for maternal and perinatal health priorities for low and middle income countries [15]. However, our prioritization exercise built consensus on 120 questions from 12 thematic areas. The results of this study provide local and context-specific questions which cannot be compared to other countries specifically; nevertheless, they are in line with what has been reported [15]. The results were general and not specific as reported in other studies since our study asked for general research questions while the other studies focused on interventions [16] [17] or specific governmental services [18].

In fact, research priority setting is an iterative process, and this is only the first step in a much longer process of refining the research priority areas into more specific questions. We note that such a process involving many individuals is open to biases that can be associated with the persons involved. However, the initial survey reached out to as many experienced and diverse stakeholders as possible. Hence this list should be reviewed and updated regularly to accommodate pertinent issues in SRHR arising from time to time.

The findings of the priority setting are also similar to the findings reported [13]. The priority area addressed adolescent violence and preventing early pregnancy, similar to findings reported elsewhere [13]. It is noted that gender-based violence that may include sexual violence, physical violence, and psychological violence reported the highest number of questions in this priority setting. The study had strengths and limitations. The strengths included the fact that the methodology was systematic and flexible; it involved stakeholders throughout the process and the possibility of revising weights and thresholds according the context. Concerns relate to the potential for a limited number of research options/questions being proposed by involving a very limited group of technical experts and stakeholders.

\section{Conclusion}

For purposes of focused prioritization, five thematic areas that would impact 
sexual and reproductive health and rights were identified. The research priority list highlights areas of concern and interest that could be relied on by researchers, policy makers, funders and other stakeholders with interest in improving SRHR services in the WHO African Region. We are hopeful that this exercise will strengthen evidence to inform decision making and appropriate responses and actions that focus on SRHR.

\section{Authors Contribution}

NT, OL, BF, MS, DK, DS, AC and EH conceptualized the exercise. KC, AM, TL, consolidated the online survey and provided technical support. All authors read and approved the final manuscript.

\section{Acknowledgements}

We thank all the representatives from countries Benin involved in the prioritization exercise; Burkina Faso, Chad, DRC, Ethiopia, Ghana, Mali, Nigeria, Rwanda, South Africa, WHO CCs, APHRC, WAHO, 1RSS. They include: Zan Souleymane, Moufalilou Aboubakar, Bokossa Alexis Richard, Gaston D. Ahounou, Dina Gbenou, Hien Clotaire, Kiemtoré Sibraogo, Traoré Isidore Tiandiogo Bassounda, Poïdigem Dadjoari, Moussa Nguetabe, Odile Awad Adam, Awad Foumsou, Kini Brigitte Nsiku, Haimanot Ambelu, Workineh Tenaye Kebede, Girma Gemechu, Mekdes Daba, Deo Roseline, Samuel Oppong, Ivy Osei, Patrick K. Aboagye, Sy Telly, Férida Mara Alpha, Ahmadou Diallo, Tessougue Fatoumata, Idrissa Cissé, Sidy Diallo, Ben Moulaye, Haidara Moussa Kamissoko, Ojo Olumuyiwa, Ufere Joy, Ikpeze Okechukwu Christian, Chris Ega, Kabuteni Theopista, John Utumatwishima, Jean Nepo Ndaruhutse, Victor Ruzindana Kenneth, Mihretu Belete, Sithembile Dlamini-Nqeketo, K. S. Dithole, Rapinyana O., Ntombi Mtshali, Mercy Pindani, Azwihangwisi Helen Mavhandu-Mudzusi, Uta Lehmann, Dr. Boniface Ushie, David Norris, Blami Dao, Issiaka Sombie, Seni Kouanda, Richard Adanu, Goma Mboungou Mierette, Mavounia Ndoko Genil, Ngwenya, Mmamoitlamo and Mncwabe Pearl.

\section{Funding}

The WHO Regional office for Africa.

\section{Conflicts of Interest}

All authors declare no competing interests.

\section{References}

[1] Gülmezoglu, A.M., et al. (2014) How to Increase Value and Reduce Waste When Research Priorities Are Set. The Lancet, 383, 156-165. https://doi.org/10.1016/S0140-6736(13)62229-1

[2] Starrs, A., Ezeh, A.C., Barker, G., et al. (2018) Accelerate Progress-Sexual and Reproductive Health and Rights for All: Report of the Guttmacher-Lancet Commis- 
sion. The Lancet, 391, 2642-2692. https://doi.org/10.1016/S0140-6736(18)30293-9

[3] Nasser, M., et al. (2013) Evidence in Agenda Setting: New Directions for the Cochrane Collaboration. Journal of Clinical Epidemiology, 66, 469-471.

https://doi.org/10.1016/j.jclinepi.2012.08.006

[4] Sablich, L. (2018) Who's Investing in Health Care R\&D?

https://www.brookings.edu/blog/techtank/2018/04/23/whos-investing-in-health-car e-rd/

[5] Seek Development. Global Health R\&D. Donor Tracker. https://donortracker.org/sector/global-health-r-and-d

[6] World Health Organization (2018) One Year on, Global Observatory on Health R\&D Identifies Striking Gaps and Inequalities. http://www.who.int/features/2018/health-research-and-development/en

[7] GBD 2015 Mortality and Causes of Death Collaborators (2016) Global, Regional, and National Life Expectancy, All-Cause Mortality, and Cause-Specific Mortality for 249 Causes of Death, 1980-2015: A Systematic Analysis for the Global Burden of Disease Study 2015. The Lancet, 388, 1459-544.

https://doi.org/10.1016/S0140-6736(16)31012-1

[8] The WHO Strategy on Research and Health 2012.

[9] Rudan, I., Kapiriri, L., Tomlinson, M., Balliet, M., Cohen, B. and Chopra, M. (2010) Evidence-Based Priority Setting for Health Care and Research: Tools to Support Policy in Maternal, Neonatal, and Child Health in Africa. PLOS Medicine, 7, e1000308. https://doi.org/10.1371/journal.pmed.1000308

[10] Klein, R. (1998) Puzzling Out Priorities. Why We Must Acknowledge That Rationing Is a Political Process. BMJ (Clinical Research ed.), 317, 959-960.

https://doi.org/10.1136/bmj.317.7164.959

[11] Priority Setting Methodologies in Health Research: A Workshop Convened by WHO's Cluster on Information, Evidence and Research (IER), Its Department for Research Policy and Cooperation (RPC) and the Special Programme for Research and Training in Tropical Diseases.

[12] Ranson, M.K. and Bennett, S.C. (2009) Priority Setting and Health Policy and Systems Research. Health Research Policy and Systems, 7, 27.

https://doi.org/10.1186/1478-4505-7-27

[13] Rudan, I., Chopra, M., Kapiriri, L., Gibson, J., Lansang, M.A., et al. (2008) Setting Priorities in Global Child Health Research Investments: Universal Challenges and Conceptual Framework. Croatian Medical Journal, 49, 398-408.

https://doi.org/10.3325/cmj.2008.3.307

[14] Ali, M., Farron, M., Quedraogo, L., Mahaini, R.K., Miller, K. and Kabra, R. (2018) Research Gaps and Emerging Priorities in Sexual and Reproductive Health in Africa and Eastern Mediterranean Regions. Reproductive Health Journal, 15, 39. https://doi.org/10.1186/s12978-018-0484-9

[15] Souza, J.P., Widmer, M., Gülmezoglu, A.M., Lawrie, T.A., Adejuyigbe, E.A., Carroli, G., Crowther, C., Currie, S.M., Dowswell, T., Hofmeyr, J., et al. (2014) Maternal and Perinatal Health Research Priorities beyond 2015: An International Survey and Prioritization Exercise. Reproductive Health, 11, 61.

https://doi.org/10.1186/1742-4755-11-61

[16] Mendis, S. and Alwan, A. (2011) Prioritized Research Agenda for Prevention and Control of Noncommunicable Diseases. World Health Organization, Geneva.

[17] de Francisco, A.A.C., Ringheim, K., Liwander, A., Peregoudov, A., Faich, H.S., et al. 
(2009) Perceived Research Priorities in Sexual and Reproductive Health for Lowand Middle-Income Countries: Results from a Survey. Global Forum for Health Research, Geneva.

[18] Dean, S., Rudan, I., Althabe, F., Webb Girard, A., Howson, C., Langer, A., Lawn, J., Reeve, M.-E., Teela, K.C., Toledano, M., et al. (2013) Setting Research Priorities for Preconception Care in Low- and Middle-Income Countries: Aiming to Reduce Maternal and Child Mortality and Morbidity. PLOS Medicine, 10, e1001508.

https://doi.org/10.1371/journal.pmed.1001508

\section{Abbreviations}

CHNRI: Child health and nutrition research initiatives; GBV: Gender based violence; WHO: World Health Organization; MDGs: Millennium development goals; SDGs: Sustainable Development Goals; UHC: Universal health coverage; SRHR: sexual and reproductive health and rights. 